УДК $330.354 ; 330.43 ; 331.56$

\title{
МОДЕЛИРОВАНИЕ ЗАКОНА ОУКЕНА В ПРИРАЩЕНИЯХ
}

\section{(C) 2013 г. Н. П. Горидько}

\section{Южно-Российский государственный технический университет (НПИ)}

С помощью регрессионного анализа показано влияние изменения уровня безработиць на вариачию валового выпуска на примере макросистемы Украины за период, включающий кризисные годы. Полученная результирующая функция свидетельствует о том, что наиболее благоприятной с точки зрения максимизачии прироста ВВП этой страны является ситуация, в которой уровень безработищы остаётся неизменным с течением времени.

Ключевые слова: экономический рост; ВВП; уровень безработищьт; закон Оукена; регрессионная модель.

The regression analysis that is presented in this paper shows the effect of changes in the unemployment rate on the variation of the gross output in the example of Ukraine macrosystem for the period, including the years of crisis. The resulting function indicates that the situation when the unemployment rate remains unchanged for a while is the most favorable for GDP growth increasing.

Key words: economic growth; GDP; unemployment rate; Okun's Law; regression model.

Экономический рост макросистем зачастую связывают со снижением уровня безработицы. Количественные характеристики такого соотношения в 60-х годах XX века на эмпирических данных исследовал Артур Оукен (Arthur Melvin Okun), в то время возглавлявший Совет экономических консультантов при Президенте США.

Современная формулировка закона Оукена такова:

$$
\frac{Y_{n}-Y^{*}}{Y^{*}}=\beta \cdot\left(u_{n}-u^{*}\right)
$$

где $Y_{n}-$ ВВП текущего года; $Y^{*}$ - потенциальный ВВП; $u_{n}$ - уровень безработицы в текущем году; $u^{*}$ - так называемая естественная норма безработицы (NAIRU - Nonaccelerating inflation rate of unemployment), т. е. уровень безработицы, при котором темп открытой инфляции может быть нулевым; $\beta$ - регрессор, вычисляемый по данным макроэкономической динамики страны (параметр Оукена).

Применение данной формулы предполагает необходимость определения $Y^{*}$ и $u^{*}$, для чего нужны дополнительные вычисления.

Результаты исследований Оукена интерпретируются в учебной литературе таким образом: «когда естественная норма безработицы составляла 4\%, каждый процент конъюнктурной безработицы уменьшал фактический ВВП на 3\%» [1, с. 208] или «в условиях депрессии прирост безработицы составляет около 1,5\% в год; при стабильно невысоких темпах роста экономики (около 2,5\%) уровень безработицы не изменяется» [2, c. 55]. Исходя из последней трактовки закона в России проведены расчёты по данным 1997 г., из которых сделан вывод о значительном недопроизводстве ВВП из-за безработицы [3, с. 149].

Формула, полученная в результате расчетов по многим развитым странам мира, исходит из того, что при ликвидации разрыва безработицы (т. е. при совпадении текущей нормы безработицы с NAIRU) разрыв ВBП исчезает, т. е. текущий реальный ВВП совпадет с потенциальным. Такая трактовка закона Оукена применима только к макросистемам, в которых наиболее дефицитным (предель- 
ным) ресурсом является живой труд, что, собственно, и имеет место в большинстве развитых стран. Однако среди развивающихся стран трудно найти такую, в которой живой труд был бы предельным ресурсом [4]. Поэтому для проведения расчетов по большинству развивающихся стран следует применять более «широкую» трактовку закона Оукена, а именно:

$$
\frac{Y_{n}-Y^{*}}{Y^{*}}=\alpha-\beta \cdot\left(u_{n}-u^{*}\right),
$$

где коэффициенты $\alpha$ и $\beta$ находятся регрессионными методами по данным экономической динамики исследуемой макросистемы.

Иногда формулу записывают в следующем виде [3, с. 149]:

$$
\frac{Y_{n}-Y_{n-1}}{Y_{n-1}} \cdot 100 \%=3 \%-2 \cdot\left(u_{n}-u_{n-1}\right),
$$

где $Y_{n-1}-$ ВВП предыдущего года; $u_{n-1}-$ уровень безработицы в предыдущем году.

Из функции (3) следует, что при неизменном уровне безработицы прирост реального ВВП будет составлять 3\% в год, а при каждом увеличении уровня безработицы на $1 \%$ темп роста реального ВВП снижается на $2 \%$.
Нашей задачей была проверка параметров регрессии, приведенных в уравнении (2), применительно к современной экономике Украины. Динамические ряды данных этой макросистемы, представленные в таблице 1, взяты из официальных сайтов Национального банка Украины и Государственной службы статистики Украины [5; 6] и включают погодовые значения рассматриваемых параметров, в том числе и за кризисные годы. С целью исключения влияния на результат инфляционного фактора объём ВВП приведен к сопоставимым ценам относительно стабильного 2001 г.

Мы будем использовать отличную от описанных выше трактовку закона Оукена, а именно - закон Оукена в приращениях:

$$
\Delta Y_{n}=\alpha+\beta \cdot \Delta u_{n}
$$

где $\Delta Y_{n}=Y_{n}-Y_{n-1}$ - годовое приращение текущего реального ВВП; $\Delta u_{n}=u_{n}-u_{n-1}-$ годовое приращение текущего уровня безработицы; $\alpha$ и $\beta$ - параметры регрессии.

Соотношение первых разностей показателей как следует из графика, приведенного на рис. 1, можно аппроксимировать как линейной, так и полиномиальной функцией.

Собственно линейная функция полу-

Показатели макросистемы Украины за 2001-2011 гг.

\begin{tabular}{|c|c|c|c|c|}
\hline Год & Объём ВВП, млрд. грн. & Уровень безработицы, \% & \multicolumn{2}{|c|}{$\begin{array}{c}\text { Первые разности } \\
\text { показателей }\end{array}$} \\
\hline$n$ & $Y_{n}$ & $u_{n}$ & $\Delta Y_{n}$ & $\Delta u_{n}$ \\
\hline 2001 & 204,2 & 10,9 & - & - \\
\hline 2002 & 214,9 & 9,6 & 10,7 & $-1,3$ \\
\hline 2003 & 235,5 & 9,1 & 20,7 & $-0,5$ \\
\hline 2004 & 264,2 & 8,6 & 28,6 & $-0,5$ \\
\hline 2005 & 271,4 & 7,2 & 7,2 & $-1,4$ \\
\hline 2006 & 291,4 & 6,8 & 20,0 & $-0,4$ \\
\hline 2007 & 314,6 & 6,9 & 23,2 & 0,1 \\
\hline 2008 & 321,8 & 6,9 & 7,2 & 0,0 \\
\hline 2009 & 274,3 & 9,6 & $-47,4$ & 2,7 \\
\hline 2010 & 285,7 & 8,8 & 11,4 & $-0,8$ \\
\hline 2011 & 300,3 & 8,6 & 14,6 & $-0,2$ \\
\hline
\end{tabular}



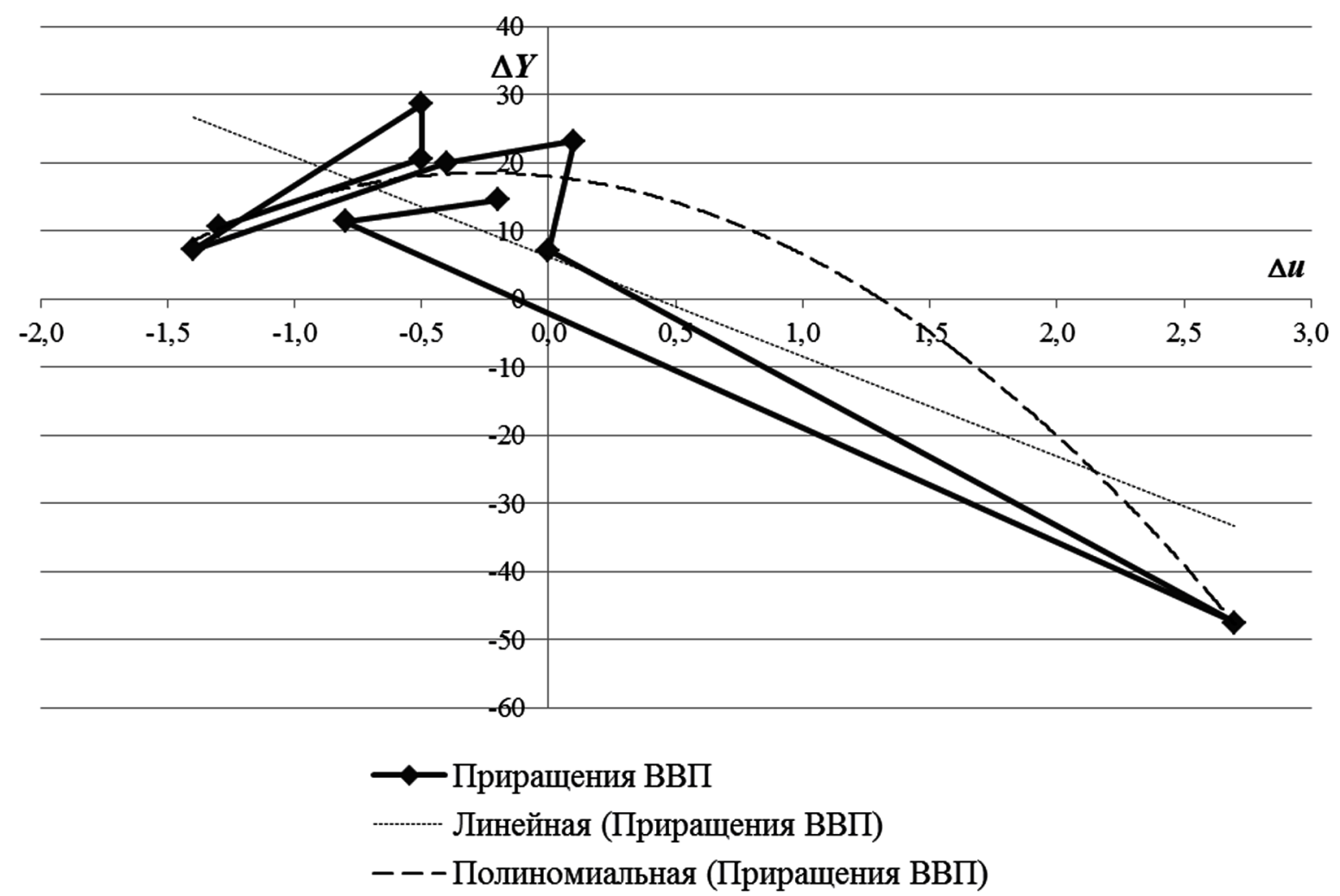

Рис. 1. Взаимосвязь первых разностей показателей объёма ВВП и уровня безработицы по макросистеме Украины 2002-2011 гг.

чена лишь благодаря данным за кризисный 2009 год, которые значительно отличаются от других значений приращений показателей и составляют именно ту «вторую точку», которая наряду с первой (объединяющей все остальные наблюдения) нужна для того, чтобы провести прямую. В этом случае функция имеет вид:

$$
\Delta Y_{n}=6,24-14,7 \cdot \Delta u_{n} .
$$

Модель имеет следующие характеристики, представленные в таблице 2: коэффициент детерминации указывает на то, что прирост безработицы объясняет вариацию прироста объёма ВВП на $62 \%$; критерий Фишера свидетельствует о соответствии вида функции исходным данным; тем не менее, с вероятностью 95\% можем говорить о том, что параметр регрессии $a$ незначим ( $t$-статистика для него меньше критического значения на 95\%-ном уровне доверия).

После исключения из модели (5) незначимого свободного члена получим следую- щую линейную функцию:

$$
\Delta Y_{n}=-15,8 \cdot \Delta u_{n} .
$$

Характеристики модели несколько ухудшились: уменьшились значения $R^{2}$ и $F$-критерия, возросла стандартная ошибка аппроксимации, но оставшийся параметр регрессии значим на уровне значимости $1 \%$ (таблица 3 ).

Исходя из модели (6), можем сделать вывод о том, что при неизменной безработице объём ВВП страны также не меняется, а увеличение уровня безработицы на 1\% влечёт за собой снижение ВВП на 15,82 млрд. грн. Тут следует сделать скидку на не очень высокие объясняющие характеристики модели и предположить, что изменение вида зависимости приведёт к их улучшению.

Следовательно, далее построим квадратичную функцию:

$$
\Delta Y_{n}=18,04-3,87 \Delta u_{n}-7,58 \cdot \Delta u_{n}^{2} \text {. }
$$

Эта модель, судя по приведенным в таблице 4 характеристикам, более качественная: коэффициент детерминации 0,92, по 
Эконометрические характеристики модели (5)

\begin{tabular}{|l|c|}
\hline \multicolumn{2}{|l|}{ Регрессионная статистика } \\
\hline Множественный $R$ & 0,787692 \\
\hline$R$-квадрат & 0,620459 \\
\hline $\begin{array}{l}\text { Нормированный } \\
R \text {-квадрат }\end{array}$ & 0,573017 \\
\hline Стандартная ошибка & 13,8983 \\
\hline Наблюдения & 10 \\
\hline
\end{tabular}

Дисперсионный анализ

\begin{tabular}{|l|c|c|c|c|c|}
\hline & $d f$ & $S S$ & $M S$ & $F$ & Значимость $F$ \\
\cline { 1 - 4 } Регрессия & 1 & 2526,207 & 2526,207 & 13,07812 & 0,006818 \\
\cline { 1 - 4 } Остаток & 8 & 1545,303 & 193,1629 & \multicolumn{2}{|l}{} \\
\cline { 1 - 4 } Итого & 9 & 4071,51 & \multicolumn{2}{|l}{}
\end{tabular}

\begin{tabular}{|l|c|c|c|c|}
\hline & Коэффициенты & $\begin{array}{c}\text { Стандартная } \\
\text { ошибка }\end{array}$ & $t$-статистика & $P$-Значение \\
\hline$\Delta Y_{n}$-пересечение & 6,243318 & 4,492785 & 1,389632 & 0,20209 \\
\hline$\Delta u_{n}$ & $-14,6559$ & 4,052656 & $-3,61637$ & 0,006818 \\
\hline
\end{tabular}

сравнению с предыдущими моделями возросло расчётное значение критерия Фишера, снизилась сумма квадратов невязок. На уровне значимости $10 \%$ незначимым оказался линейный член.

Исключая незначимый параметр из модели (7), получим формулу:

$$
\Delta Y_{n}=20,69-9,01 \cdot \Delta u_{n}^{2} .
$$

В целом модель (8), несмотря на некоторое ухудшение объясняющих характеристик (таблица 5), адекватно описывает исходные данные, параметры регрессии в ней значимы на уровне значимости $1 \%$.

Функция (8) по сравнению с моделью (6) позволяет сделать несколько другие выводы, обусловленные самим её видом: при неизменном уровне безработицы приращение ВВП в стране составляло 20,69 млрд. грн. в год в среднем за исследуемый период. Поскольку модель наиболее качественная из всех полученных, мы будем считать этот вывод окончательным. Поделив параметр $\alpha$ на среднее за период 2001-2011 гг. значение объёма ВВП за исследуемый период, равное 277,41 млрд. грн., рассчитаем средний относительный прирост (темп роста) экономики в условиях неизменной безработицы, он равен 7,5\%. Таким образом, экономика Украины, несмотря на годы кризиса, показывала рост значительно выше, чем, например, экономика США 60-х годов прошлого века.

Точка $(0 ; 20,69)$ - экстремум квадратичной функции, а, следовательно, для экономического развития Украины резкое изменение уровня безработицы в любую сторону приводит к уменьшению возможного прироста ВВП. Увеличение безработицы, как правило, сопровождает рецессию, и наш вывод в этом отношении естественен. В то же время уменьшение безработицы может стать предпосылкой неэффективного использования живого труда, который в Украине не является предельным ресурсом. 
Эконометрические характеристики модели (6)

Таблица 3

\begin{tabular}{|l|c|}
\hline \multicolumn{2}{|l|}{ Регрессионная статистика } \\
\hline Множественный $R$ & 0,784867 \\
\hline$R$-квадрат & 0,616017 \\
\hline $\begin{array}{l}\text { Нормированный } \\
R \text {-квадрат }\end{array}$ & 0,504906 \\
\hline Стандартная ошибка & 14,59953 \\
\hline Наблюдения & 10 \\
\hline
\end{tabular}

Дисперсионный анализ

\begin{tabular}{|l|c|c|c|c|c|}
\hline & $d f$ & $S S$ & $M S$ & $F$ & Значимость $F$ \\
\cline { 1 - 4 } Регрессия & 1 & 3077,518 & 3077,518 & 14,43853 & 0,005238 \\
\hline Остаток & 9 & 1918,315 & 213,1461 & \multicolumn{2}{|l}{} \\
\cline { 1 - 4 } Итого & 10 & 4995,833 & \multicolumn{2}{|l}{}
\end{tabular}

\begin{tabular}{|l|l|c|c|c|}
\hline & Коэффициенты & $\begin{array}{c}\text { Стандартная } \\
\text { ошибка }\end{array}$ & $t$-статистика & $P$-Значение \\
\hline$\Delta Y_{n}$-пересечение & & & & \\
\hline$\Delta u_{n}$ & $-15,8243$ & 4,164499 & $-3,79981$ & 0,004219 \\
\hline
\end{tabular}


Таблица 4

Эконометрические характеристики модели (7)

\begin{tabular}{|l|c|}
\hline \multicolumn{2}{|l|}{ Регрессионная статистика } \\
\hline Множественный $R$ & 0,961108 \\
\hline$R$-квадрат & 0,923729 \\
\hline $\begin{array}{l}\text { Нормированный } \\
R \text {-квадрат }\end{array}$ & 0,901938 \\
\hline Стандартная ошибка & 6,660508 \\
\hline Наблюдения & 10 \\
\hline
\end{tabular}

Дисперсионный анализ

\begin{tabular}{|l|c|c|c|c|c|}
\hline & $d f$ & $S S$ & $M S$ & $F$ & Значимость $F$ \\
\cline { 1 - 4 } Регрессия & 2 & 3760,973 & 1880,487 & 42,38923 & 0,000123 \\
\cline { 1 - 4 } Остаток & 7 & 310,5366 & 44,36237 & \multicolumn{2}{|c}{} \\
\cline { 1 - 4 } Итого & 9 & 4071,51 & \multicolumn{2}{|c}{}
\end{tabular}

\begin{tabular}{|l|c|c|c|c|}
\hline & Коэффициенты & $\begin{array}{c}\text { Стандартная } \\
\text { ошибка }\end{array}$ & $t$-статистика & $P$-Значение \\
\hline$\Delta Y_{n}$-пересечение & 18,04156 & 3,10433 & 5,811741 & 0,000656 \\
\hline$\Delta u_{n}$ & $-3,86823$ & 2,820113 & $-1,37166$ & 0,212516 \\
\hline$\Delta u_{n}{ }^{2}$ & $-7,58103$ & 1,436954 & $-5,27576$ & 0,001153 \\
\hline
\end{tabular}


Таблица 5

\section{Эконометрические характеристики модели (8)}

\begin{tabular}{|l|c|}
\hline Регрессионная статистика \\
\hline Множественный $R$ & 0,950384 \\
\hline$R$-квадрат & 0,90323 \\
\hline $\begin{array}{l}\text { Нормированный } \\
R \text {-квадрат }\end{array}$ & 0,891133 \\
\hline Стандартная ошибка & 7,01785 \\
\hline Наблюдения & 10 \\
\hline
\end{tabular}

Дисперсионный анализ

\begin{tabular}{|c|c|c|c|c|c|}
\hline & $d f$ & $S S$ & $M S$ & $F$ & Значимость $F$ \\
\hline Регрессия & 1 & 3677,508 & 3677,508 & 74,66988 & $2,5 \mathrm{E}-05$ \\
\hline Остаток & 8 & 394,0017 & 49,25022 & & \\
\hline Итого & 9 & 4071,51 & & & \\
\hline
\end{tabular}

\begin{tabular}{|l|c|c|c|c|}
\hline & Коэффициенты & $\begin{array}{c}\text { Стандартная } \\
\text { ошибка }\end{array}$ & $t$-статистика & $P$-Значение \\
\hline$\Delta Y_{n}$-пересечение & 20,68762 & 2,562655 & 8,072731 & $4,09 \mathrm{E}-05$ \\
\hline$\Delta u_{n}{ }^{2}$ & $-9,01013$ & 1,042698 & $-8,64117$ & $2,5 \mathrm{E}-05$ \\
\hline
\end{tabular}

\section{Литература}

1. Тарасевич Л. С., Гребенников П. И., Леусский А. И. Макроэкономика: Учебник. - 6-е изд., испр. и доп. - М.: Высшее образование, 2005 . - 654 с.

2. Агапова Т. А., Серегина С. Ф. Макроэкономика: Учебник. / Под общ. ред. д.э.н., проф. А. В. Сидоровича; МГУ им. М. В. Ломоносова. - 5-е изд., перераб. и доп. - М.: Издательство «Дело и сервис», 2002. - 448 c.

3. Макроэкономика. Теория и российская практика: учебник. - 5-е изд., перераб. и доп. / Под ред. А. Г.Грязновой и Н. Н. Дум- ной. - М.: КНОРУС, 2005. - 688 c.

4. Нижегородиев Р. М. Основы экономической теории: Обзорный курс лекций для студентов экономических специальностей. - М.: Доброе слово, 2008. - 216 с.

5. Реальный сектор [Электронный ресурс] / Национальный банк Украины. - Pежим доступа: http://bank.gov.ua/control/uk/ publish/category?cat_id=57896, свободный. Загл. с экрана.

6. Государственная служба статистики Украины [Электронный ресурс]. / Официальный сайт. - Режим доступа: http://ukrstat. gov.ua, свободный. - Загл. с экрана. 


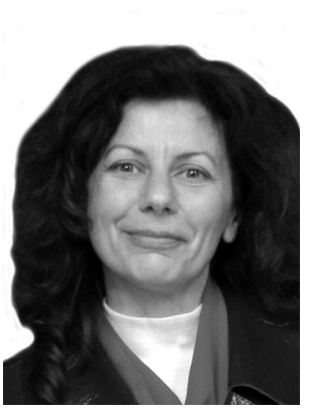

Нина Павловна Горидько - соискатель Южно-Российского государственного технического университета (НПИ). Автор и соавтор 85 научных публикаций, в том числе 4 монографий. Специалист в области экономической статистики, эконометрики, информационных технологий в экономике и управлении бизнесом.

Nina Pavlovna Goridko - competitor for Candidate's degree at the South-Russian Technical State University (NPI). The author of 85 scientific publications, including 4 monographs. Majors in economic statistics, econometrics, information technologies for management and decision-making.

18000, Украіна, г. Черкассы, ул. Энгельса, д. 164

164 Engelsa st., 18000, Cherkassy, Ukraine

Тел./факс: + 38 (0472) 71-99-51, 71-99-42; e-mail: horidko@mail.ru 